Review

\title{
Human Organoids as a Promising Platform for Fighting COVID-19
}

\author{
Dong Chen ${ }^{1}$, Xi Su${ }^{1}$, Haibo Chen², Siyan Chen ${ }^{3}$, Yongsheng Zhao ${ }^{\natural 凶}$, Wei Wei ${ }^{1 凶}$ \\ 1. Department of Thyroid and Breast Surgery, Peking University Shenzhen Hospital, Shenzhen 518036, China. \\ 2. Department of Nuclear Medicine, Peking University Shenzhen Hospital, Shenzhen 518036, China. \\ 3. College of Life Sciences and Oceanography, Shenzhen University, Shenzhen 518060, China.
}

$\square$ Corresponding author: Yongsheng Zhao, Department of Nuclear Medicine, Peking University Shenzhen Hospital, No.1120, Lianhua Road, Futian District, Shenzhen 518036, China. E-mail: zhaoys69@126.com; Wei Wei, Department of Thyroid and Breast Surgery, Peking University Shenzhen Hospital, No.1120, Lianhua Road, Futian District, Shenzhen 518036, China. E-mail: rxwei1123@163.com.

(1) The author(s). This is an open access article distributed under the terms of the Creative Commons Attribution License (https://creativecommons.org/licenses/by/4.0/). See http://ivyspring.com/terms for full terms and conditions.

Received: 2021.07.15; Accepted: 2021.12.06; Published: 2022.01.01

\begin{abstract}
The coronavirus disease 2019 (COVID-19) global pandemic evoked by the severe acute respiratory syndrome coronavirus 2 (SARS-CoV-2) has triggered a major public health problem with significant morbidity and mortality. Understanding the pathogenesis and molecular mechanisms underlying this novel virus is crucial for both fundamental research and clinical trials in order to devise effective therapies and vaccination regimens. Basic research on SARS-CoV-2 largely depends on ex vivo models that allow viral invasion and replication. Organoid models are now emerging as a valuable tool to investigate viral biology and disease progression, serving as an efficient platform to investigate potential therapies for COVID-19. Here, we summarize various human stem cell-derived organoid types employed in SARS-CoV-2 studies. We highlight key findings from these models, including cell tropisms and molecular mechanisms in viral infection. We also describe their use in identifying potential therapeutic agents against SARS-CoV-2. As more and more advanced organoids emerge, they will facilitate the understanding of disease pathogenesis for drug development in this dreaded pandemic.
\end{abstract}

Key words: organoid; SARS-CoV-2; COVID-19; infection; drug screening

\section{Introduction}

The coronavirus disease 2019 (COVID-19) pneumonia epidemic caused by the severe acute respiratory syndrome coronavirus 2 (SARS-CoV-2) has become the worst public health threat in the current century. Treatment strategies for prevention and intervention are a matter of urgency. Although many clinical trials are currently underway, preclinical research on in vitro models is also needed to allow us to better understand virus infections and to test drugs and vaccines for safety and efficacy.

Until now, there has only been a limited number of animal models available in SARS-CoV-2 research. The most susceptible animals to this virus are cats [1], ferrets [1, 2], rhesus macaques [3], cynomolgus macaques [4], and golden hamsters [5]. SARS-CoV-2 utilizes angiotensin converting enzyme 2 (ACE2) for cellular entry and the cell surface transmembrane serine protease 2 (TMPRSS2) for spike protein priming [6, 7]. Transgenic mice expressing human ACE2 can be a good option to study COVID-19 [8]. Nevertheless, animal-based studies are generally expensive and lengthy, and fail to fully mimic human physiology due to species specificity.

Classic cell lines are a great alternative to animal models. In fact, much of the insight on the pathogenesis and drug responses of SARS-CoV-2 has been obtained using numerous cell lines, such as Vero (kidney epithelial cells), Caco2 (intestinal cells), Calu3 (pulmonary cells), and Huh7 (hepatic cells) [7, 9, 10]. However, cell lines are mostly of malignant origin and cannot simulate cell-cell and cell-matrix interactions. The in vivo infection status and pathological features may also be poorly recapitulated in these two-dimensional (2D) cultures.

A range of recent studies on COVID-19 highlights the value of more physiological in vitro 
models, called organoids. Organoids are miniaturized, three-dimensional (3D) tissue models that derived from induced pluripotent stem cells (iPSCs), embryonic stem cells (ESCs), or multipotent adult stem cells (ASCs) [11, 12]. Importantly, they consist of various cell types and faithfully recapitulate the essential structure and physiological characteristics of the parental organ in a dish $[13,14]$. Organoids are powerful tools for disease modeling in vitro, providing a more flexible, efficient, and large-scale drug screening platform than in vivo models. They are also ethically humane tools used to study physiology and disease, including viral infections.

\section{Organoids in virology}

In virology, organoids are particularly useful as they permit studies on viruses that are difficult to cultivate. Organoid models have been shown to be an excellent model to study viral infections and host-virus interactions [15-23]. Generating various organoid models from human tissues has become more important in studying viral infections as patients show signs of systemic symptoms in addition to respiratory infection.

Most of airborne viruses enter human body by infecting epithelial cells. Organoids derived from oral mucosa, airway, lung, and intestines have been used to model viral infection and replication. Organoids derived from human oral mucosal maintain morphologic and functional characteristics of their parental tissues, and have been shown to be productively infected by human papillomavirus (HPV) and herpes simplex virus (HSV) [16]. Human airway organoids have emerged as a valuable tool to assess the susceptibility of animal influenza viruses $[23,24]$. Zhou, et al., proved that the differentiated human airway organoids are susceptible to the human-infective influenza viruses H7N9 and H1N1, while avian $\mathrm{H} 7 \mathrm{~N} 2$ and swine H1N1 influenza viruses showed lower replication levels [23]. Another study used human airway organoid cultures to measure replication competence, tissue tropism and host response to human influenza virus [24]. Moreover, Sachs, et al., used human airway organoids to show dramatic epithelial remodeling after respiratory syncytial virus (RSV) infection [21]. Noroviruses are a major cause of gastroenteritis in the world. Human stem cell-derived intestinal organoids have become the first ex vivo infection model to support noroviruses replication [18]. Indeed, the human intestinal organoid cultivation system recapitulates the physiologically active intestinal epithelium, and allows studies of norovirus replication efficiency in vitro [17]. This model was also used to confirm that the intestines are a target organ for Middle East respiratory syndrome coronavirus (MERS-CoV) [25].

During the 2015 Zika virus (ZIKV) outbreak, human iPSC-derived cerebral organoids were adopted to provide proof that this virus selectively replicates in the developing brain, preferentially infecting neural cell precursors, leading to congenital abnormalities including microcephaly [22, 26, 27]. These studies provide the explanation as to why the virus has a greater detrimental effect on the fetal brain compared to the postnatal brain. By using cortical organoids to infect cytomegalovirus, Sison, et al., found organoid structure alterations and disruptions in specific marker expression [28]. Furthermore, human liver organoids also emerged as a promising personalized infection model in the treatment of hepatitis B virus (HBV). By co-culture of human iPSCderived endodermal, mesenchymal and endothelial cells with a chemically defined medium in a 3D system, Nie and colleagues generated the functional liver organoids that can inherit the genetic background of donors and reproduce host-virus interactions by simulating HBV propagation and the virus-induced hepatic dysfunction [29].

\section{Human organoids in studying SARS-CoV-2 infection}

Besides lung injury caused by SARS-CoV-2, symptoms have also been noted in multiple other organs, including brain, liver, intestine, kidney, eye, heart, and blood vessels (Figure 1). Many research groups have utilized organoid technologies to understand the tissue tropism and cellular response of SARS-CoV-2 and the damage caused. Organoids can be established from either human pluripotent stem cells (PSCs) including ESCs and iPSCs, or multipotent adult tissue stem cells (ASCs). SARS-CoV-2 infection and replication have been studied in PSC- and ASC-based organoids derived from a wide range of organs (Table 1). Organoid models are proving their worth in verifying the safety and efficacy of antiviral therapies as these in vitro models can exploit a priori knowledge on virus biology, and allow for the testing of well-known viral inhibitors and the discovery of new drugs (Figure 2).

\section{Lung organoids}

SARS-CoV-2 has been demonstrated to employ two key host proteins, ACE2 and TMPRSS2, to bind and infect host cells [6, 7]. ACE2 and TMPRSS2 have been shown to be highly expressed in human airway organoids [23,30], indicating that they are suitable for SARS-CoV-2 research. Air-liquid interface (ALI) cultures of human airway organoids were readily infected by the addition of SARS-CoV-2 to the apical side [31]. The virus infection was observed in ciliated 
cells but not in goblet cells, suggesting that ciliated cells are the main targets of the virus [31]. In a recent study, alveolar cells, basal cells, and rare neuroendocrine cells were grown from human fetal lung bud tip progenitor organoids [32]. Most of the infected cells were alveolar type II cells, and a low dose of interferon lambda 1 (IFN- $\lambda 1$ ) was shown to reduce viral replication. Therefore, ciliated cells and alveolar cells are susceptible to SARS-CoV-2 infection, and ciliated cells could be infected prior to the alveoli [32]. Ebisudani et al., established an efficient ASC-based alveolosphere culture system. These alveolospheres express ACE2 at both RNA and protein levels, and maintain the robust infection efficiency of SARS-CoV-2 even after long-term cultivation [33]. Salahudeen, et al., generated human distal lung organoids with apical-out morphology to present ACE2 on the exposed external surface, allowing them to be infected by SARS-CoV-2 [34]. Contrary to Lamers's work [31], goblet cells, but not ciliated cells, were infectable in their organoid cultures [34]. Additionally, ASC-derived human lung organoids consisting of both proximal and distal airway epithelia have been established, and the proximal airway epithelium has been shown to be more permissive to SARS-CoV-2 infection [35]. Han, et al., demonstrated SARS-CoV-2 entry and infection in human ESC-derived lung organoids, which are mainly composed of alveolar type-I (AT1) cells, alveolar type-II (AT2) cells, stroma cells, neuroendocrine cells, and airway epithelial cells [36]. Gene ontology analysis of infected lung organoids revealed that most upregulated genes were associated with immune response. Several chemokines and cytokines, including tumor necrosis factor (TNF), interleukin (IL), as well as nuclear factor kappa beta (NF-kB) were observably upregulation [36, 37]. A progressive increase of cell death in lung organoids became evident at 72 hours post infection, and this was further validated by immunostaining experiments [37].

Lung organoids derived from human pluripotent stem cells (hPSCs) were permissive to mass production, cryopreservation, and genetic manipulation [38]. They also allowed researchers to assess the antiviral effects of COVID-19 candidate drugs [33, 36, 37, 39, 40]. Remdesivir, a nucleotide analogue prodrug used to inhibit viral replication, has been shown to greatly reduce the production of infectious virus particles in both human airway organoids and alveolar organoids, while camostat (a TMPRSS2 inhibitor) has been shown to slightly decrease the production of the virus in airway organoids but not alveolar organoids [37]. Remdesivir has also been shown to inhibit SARS-CoV-2 replication in human alveolospheres at the concentration comparable with the circulating drug level [33]. Suzuki, et al., found a reduction of viral copy number in the infected bronchial organoids with treatment of camostat [40]. Neutralizing antibody CB6, one of the promising neutralizing antibodies to treat COVID-19 [41], significantly decreased the production of infectious viral in lung organoids [37]. In addition, pre-treatment of lung organoids with imatinib, chloroquine, mycophenolic acid (MPA), and quinacrine dihydrochloride (QNHC) effectively blocked the ACE2 cleavage site, suggesting a potential role in decreasing SARS-CoV-2 infection [36]. Human lung organoids have also been used to test the efficacy of candidate antiandrogenic drugs, such as finasteride, ketoconazole, and dutasteride, in resisting SARS-CoV-2 infection. These drugs have been certified to downregulate the expression of ACE2 in lung organoids, and therefore to reduce susceptibility to the virus [39]. Overall, human lung organoids can serve as an excellent model to investigate SARS-CoV-2 infection and to screen and discover candidate COVID-19 therapeutics.

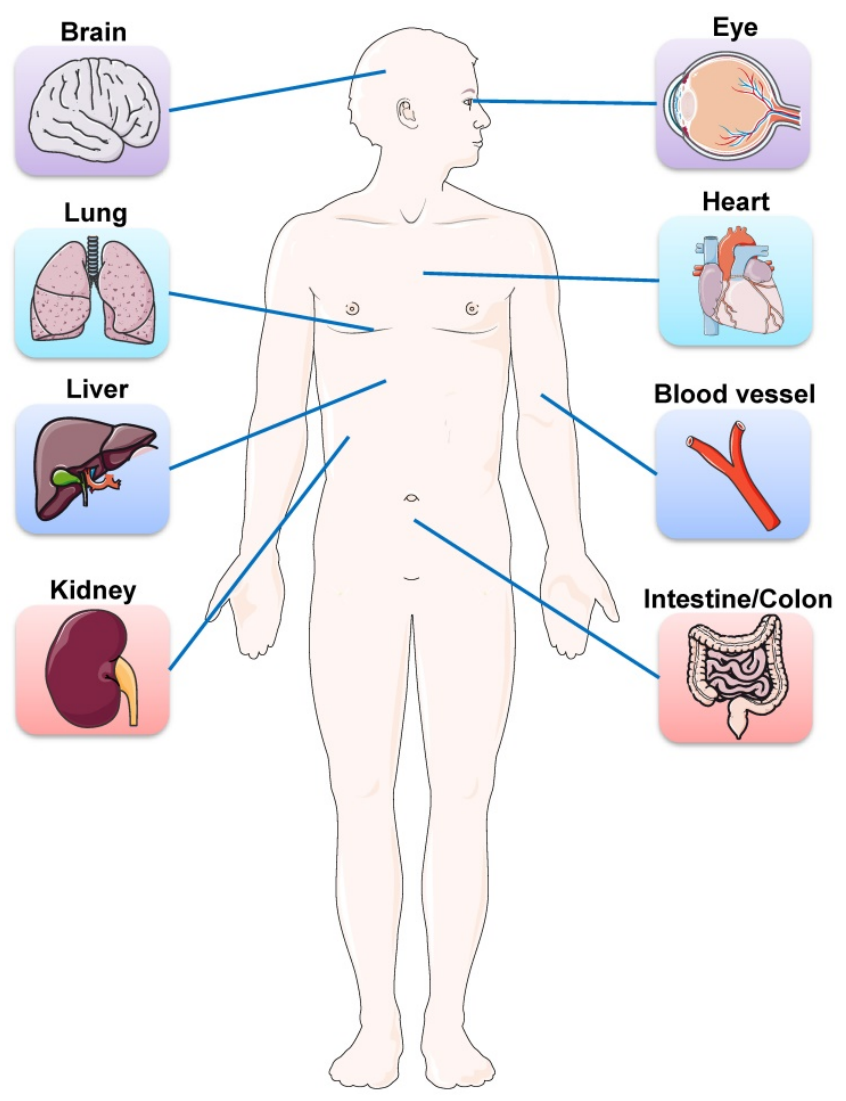

Figure 1. Schematic representation of the main organs affected by SARS-COV-2. Besides lung injury caused by SARS-CoV-2, symptoms have also been noted in multiple other organs, including brain, eye, heart, liver, intestine, kidney, and blood vessels. 
Table 1. List of human PSC-derived organoids used to study SARS-CoV-2 infection

\begin{tabular}{|c|c|c|c|}
\hline Organoid type & Origin & Key points & Drug candidates \\
\hline $\begin{array}{l}\text { Lung organoids/ } \\
\text { Airway organoids/ } \\
\text { Alveolar organoids }\end{array}$ & $\begin{array}{l}\text { Human embryonic } \\
\text { stem cells }\end{array}$ & $\begin{array}{l}\text { SARS-CoV-2 entry and infection in lung organoids, which are mainly composed of } \\
\text { alveolar type-I, alveolar type-II, stroma, neuroendocrine, and airway epithelial cells } \\
\text { [36]; } \\
\text { SARS-CoV-2 were shown to infect ciliated, club, and alveolar type } 2 \text { cells in airway } \\
\text { and alveolar organoids, and induce the downregulation of the metabolic processes } \\
\text { and the upregulation of immune response [37]; } \\
\text { Remdesivir was shown to greatly reduce the production of infectious virus particles } \\
\text { in airway and alveolar organoids [37]; } \\
\text { Androgen signaling inhibition reduces SARS-CoV-2 infection in lung organoids [39]. }\end{array}$ & $\begin{array}{l}\text { Remdesivir; } \\
\text { Imatinib; } \\
\text { Camostat; } \\
\text { Mycophenolic acid (MPA); } \\
\text { Quinacrine dihydrochloride (QNHC); } \\
\text { Chloroquine; } \\
\text { Neutralizing antibodies; } \\
\text { Dutasteride; } \\
\text { Ketoconazole; } \\
\text { Finasteride. }\end{array}$ \\
\hline $\begin{array}{l}\text { Intestinal organoids/ } \\
\text { Colonic organoids }\end{array}$ & $\begin{array}{l}\text { Human embryonic } \\
\text { stem cells }\end{array}$ & $\begin{array}{l}\text { Colonic organoids are permissive to infection by SARS-CoV-2 [36]; } \\
\text { Enterocytes express ACE2 and are the cell types most susceptible to SARS-CoV-2 } \\
\text { infection [36]; } \\
\text { Remdesivir and EK1 inhibited SARS-CoV-2 infection and replication in intestinal } \\
\text { organoids [45]. }\end{array}$ & $\begin{array}{l}\text { Remdesivir; } \\
\text { Imatinib; } \\
\text { Mycophenolic acid (MPA); } \\
\text { Quinacrine dihydrochloride (QNHC); } \\
\text { Famotidine; } \\
\text { EK1. }\end{array}$ \\
\hline $\begin{array}{l}\text { Brain } \\
\text { organoids/Choroid } \\
\text { plexus organoids }\end{array}$ & $\begin{array}{l}\text { Human embryonic } \\
\text { stem cells; } \\
\text { Human induced } \\
\text { pluripotent stem cells }\end{array}$ & $\begin{array}{l}\text { Brain organoids are permissive to infection but do not support active viral replication } \\
\text { [52]; } \\
\text { Neuronal infection was inhibited by blocking ACE2 with antibodies or by } \\
\text { administering cerebrospinal fluid from a COVID-19 patient [54]; } \\
\text { SARS-CoV-2 can directly target cortical neurons and neural progenitor cells in brain } \\
\text { organoids [55]; } \\
\text { Extensive viral protein expression and infectious viral particles were detected in } \\
\text { brain organoids infected with SARS-CoV-2 [56]; } \\
\text { Choroid plexus organoids are permissive to productive infection, leading to } \\
\text { transcriptional upregulation of inflammatory genes [57]; } \\
\text { SARS-CoV-2 infects choroid plexus, leading to damage of this brain barrier [59]; } \\
\text { Sofosbuvir protects brain organoid from SARS-CoV-2 infection [61]. }\end{array}$ & $\begin{array}{l}\text { IgG antibodies present in the } \\
\text { cerebrospinal fluid of COVID-19 } \\
\text { patients; } \\
\text { Sofosbuvir. }\end{array}$ \\
\hline Liver organoids & $\begin{array}{l}\text { Human induced } \\
\text { pluripotent stem cells }\end{array}$ & $\begin{array}{l}\text { Human hepatocyte and cholangiocyte organoids are highly permissive to } \\
\text { SARS-CoV-2 infection [63]; } \\
\text { Liver organoids show similar chemokine response as COVID-19 patients [63]. }\end{array}$ & / \\
\hline Kidney organoids & $\begin{array}{l}\text { Human embryonic } \\
\text { stem cells }\end{array}$ & $\begin{array}{l}\text { Kidney organoids express ACE2 and TMPRSS2 [68]; } \\
\text { SARS-CoV-2 can directly infect kidney organoids [68]; } \\
\text { Human recombinant soluble ACE2 reduce SARS-CoV-2 infection in kidney } \\
\text { organoids [68, } 71] \text {; } \\
\text { Combination therapy using Remdesivir with recombinant soluble ACE2 reduces } \\
\text { virus entry and replication [70]. }\end{array}$ & $\begin{array}{l}\text { Human recombinant soluble ACE2; } \\
\text { Remdesivir. }\end{array}$ \\
\hline Cardiac organoids & $\begin{array}{l}\text { Human embryonic } \\
\text { stem cells }\end{array}$ & $\begin{array}{l}\text { BET inhibitors reduce ACE2 expression, decrease transcription of genes in the viral } \\
\text { response, and block SARS-CoV-2 infection of cardiomyocytes and } \\
\text { inflammation-induced cardiac dysfunction [76]. }\end{array}$ & $\begin{array}{l}\text { Bromodomain and extraterminal } \\
\text { family inhibitors (BETi). }\end{array}$ \\
\hline $\begin{array}{l}\text { Blood vessel } \\
\text { organoids }\end{array}$ & $\begin{array}{l}\text { Human induced } \\
\text { pluripotent stem cells } \\
\text { composed of vascular } \\
\text { networks of } \\
\text { endothelial cells }\end{array}$ & $\begin{array}{l}\text { Human blood vessel organoids were highly susceptible to SARS-CoV-2 infection can } \\
\text { be inhibited in an ACE2-dependent manner [68] }\end{array}$ & Human recombinant soluble ACE2. \\
\hline Eye organoids & $\begin{array}{l}\text { Human induced } \\
\text { pluripotent stem cells } \\
\text { Human embryonic } \\
\text { stem cells }\end{array}$ & $\begin{array}{l}\text { The limbus was most susceptible to SARS-CoV-2 infection due to the high expression } \\
\text { of ACE2 and TMPRSS2 [84]; } \\
\text { Interferon response type I and III is suppressed upon infection with SARS-CoV-2 [84]. }\end{array}$ & \\
\hline
\end{tabular}

Table 2. List of ASC-derived organoids used to study SARS-CoV-2 infection

\begin{tabular}{|c|c|c|c|}
\hline Organoid type & Origin & Key points & Drug candidates \\
\hline $\begin{array}{l}\text { Airway organoids/ } \\
\text { Bronchial } \\
\text { organoids/Distal } \\
\text { lung organoids/ } \\
\text { Fetal lung bud tip } \\
\text { organoids/ } \\
\text { Alveolospheres }\end{array}$ & $\begin{array}{l}\text { Adult small airway } \\
\text { donor; } \\
\text { Normal human bronchial } \\
\text { epithelial cells; } \\
\text { Distal airway cells from } \\
\text { patient lung tissue; } \\
\text { Fetal lung donors; } \\
\text { Normal lung tissues of } \\
\text { patients }\end{array}$ & $\begin{array}{l}\text { Ciliated cells and alveolar cells are susceptible to SARS-CoV-2 infection, and ciliated cells could be } \\
\text { infected prior to the alveoli [31,32]; } \\
\text { Human alveolospheres express ACE2 and allow robust SARS-CoV-2 infection [33]; } \\
\text { Remdesivir inhibits SARS-CoV-2 replication in alveolospheres [33]; } \\
\text { Distal lung organoids with apical-out morphology to present ACE2 on the exposed external surface, } \\
\text { allowing SARS-CoV-2 infection [34]; } \\
\text { Goblet cells but not ciliated cells were infectable in organoid cultures [34]; } \\
\text { ASC-derived lung organoids consisting of both proximal and distal airway epithelia, and the proximal } \\
\text { airway epithelium are more permissive to SARS-CoV-2 infection [35]; } \\
\text { ACE2 and TMPRSS2 are highly expressed in bronchial organoids [40]; } \\
\text { A reduction of viral copy number in the infected bronchial organoids with treatment of camostat [40]; } \\
\text { Not only intracellular viral genome, but also progeny virus, cytotoxicity, pyknotic cells, and moderate } \\
\text { increases of the type I interferon signal can be observed after SARS-CoV-2 infection [40]. }\end{array}$ & $\begin{array}{l}\text { Remdesivir; } \\
\text { Lopinavir; } \\
\text { Nelfinavir; } \\
\text { Camostat }\end{array}$ \\
\hline $\begin{array}{l}\text { Intestinal organoids/ } \\
\text { Colonic organoids }\end{array}$ & $\begin{array}{l}\text { Normal intestinal and } \\
\text { colonic samples from } \\
\text { patients }\end{array}$ & $\begin{array}{l}\text { Enterocytes produced infectious viral particles, and induced a generic viral response [31]; } \\
\text { SARS-CoV-2 was able to infect human intestinal organoids, leading to progressive cytopathic effects } \\
\text { with virus replication over time [43]; } \\
\text { Duodenum- and ileum-derived organoids are permissive to infection and support robust viral } \\
\text { replication [44]; } \\
\text { Pre-treatment of colon-derived organoids with both IFN- } \beta 1 \text { and IFN- } \lambda \text { significantly blocked } \\
\text { SARS-CoV-2 infection and this was associated with a decrease in viral genome copy number [49]. }\end{array}$ & / \\
\hline $\begin{array}{l}\text { Liver ductal } \\
\text { organoids }\end{array}$ & $\begin{array}{l}\text { Primary bile ducts } \\
\text { isolated from human liver } \\
\text { biopsies }\end{array}$ & $\begin{array}{l}\text { ACE2 and TMPRSS2 are involved in viral entry [64]; } \\
\text { SARS-CoV-2 infection impairs bile acid transportation functions [64]. }\end{array}$ & / \\
\hline
\end{tabular}




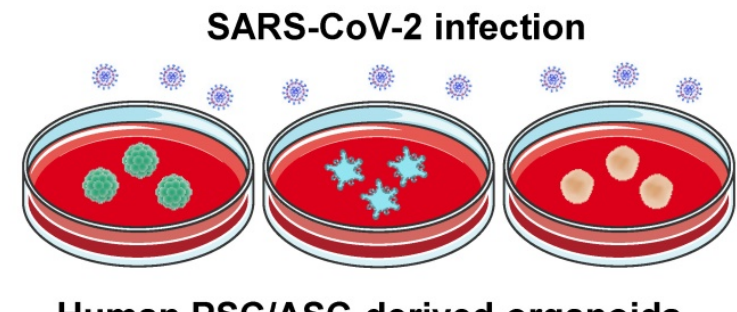

Human PSCIASC-derived organoids
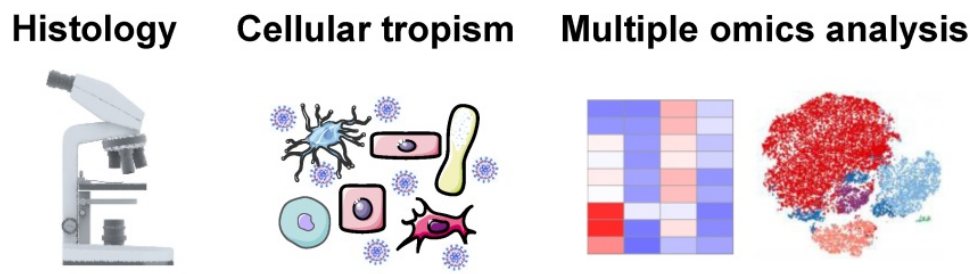

\section{Drug screening}
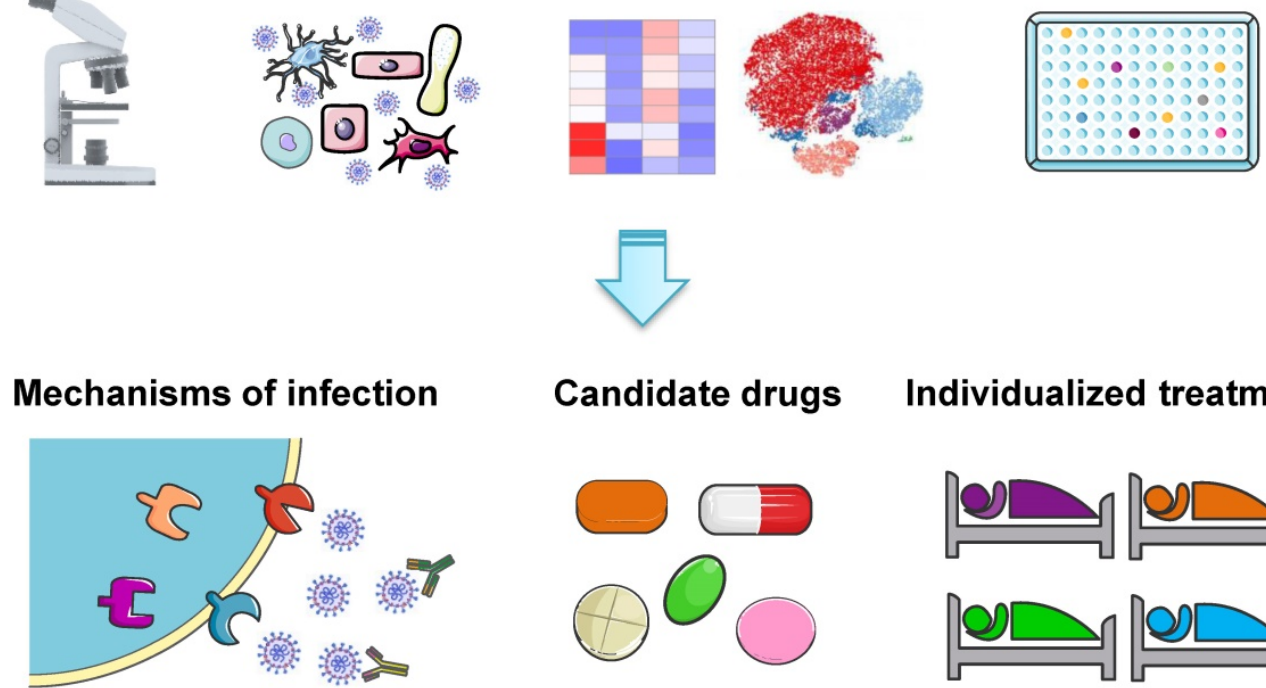

Figure 2. Common analyses and key applications of human PSC- and ASC-derived organoid platforms in COVID-19 research. Various organoids derived from PSCs or ASCs have been established to study SARS-CoV-2 infection. Organoid models are commonly used to investigate SARS-CoV-2 tropism and COVID-19 pathophysiology across different organs, as well as to verify the safety and efficacy of candidate drugs and screen new therapeutic strategies. Furthermore, patient-derived organoids may potentially serve as a platform to test the efficacy of antiviral drugs for individual patients.

\section{Intestinal organoids}

Apart from respiratory illnesses, gastrointestinal symptoms have also been identified in a subset of patients [42], indicating that the gastrointestinal tract may be a potential entry route for SARS-CoV-2. Many kinds of bats are disreputable carriers of zoonotic viruses that occasionally spread to humans, including coronaviruses. Based on the close relation of SARS-CoV-2 to SARS-CoV identified in bat species, intestinal organoids were established from human and the horseshoe bat Rhinolophus sinicus, and their sensitivities to SARS-CoV-2 infection were examined for the first time [43]. Both human and bat intestinal organoids were successfully infected by SARS-CoV-2 isolated from COVID-19 patients, leading to progressive cytopathic effects after virus replication. In addition, the expression of ACE2 and TMPRSS2 were significantly increased upon induction of organoid differentiation, indicating that SARS-CoV-2 infection occurs in differentiated cells [43]. These findings are consistent with an independent study that revealed infection and replication of the virus in the enterocytes of human small intestinal organoids [31]. As expected, ACE2 is highly expressed in differentiated enterocytes. Infected enterocytes produced viral particles, and elicited a significant upregulation of viral response genes, probably via cytoplasmic sensing of the viral RNA genome [31]. Human ESC-derived colonic organoids were also readily infected by SARS-CoV-2 [36]. Transcriptional profiling of colonic organoids indicated that enterocytes were the cell types most susceptible to SARS-CoV-2-entry virus [36]. In addition, human duodenum- and ileum-derived organoids were permissive to SARS-CoV-2 infection, and the two mucosa-specific serine proteases, TMPRSS2 and TMPRSS4, activated SARS-CoV-2 spike protein and facilitated virus entry into host cells [44]. These studies used human intestinal organoids to support clinical evidence that the gastrointestinal tract is a possible transmission route of SARS-CoV-2. 
Several studies have employed intestinal organoids to test drug candidates that might ameliorate gastrointestinal illnesses in the clinic. Krüger and colleagues [45] utilized ESC-derived intestinal organoids to test the efficiency of three candidate drugs: remdesivir [46], famotidine [47] and EK1 [48]. Results of this study indicate that remdesivir and EK1, but not famotidine, inhibited viral infection and replication [45]. Similar to the drug reaction in lung organoids, the three drug candidates imatinib, mycophenolic acid and quinacrine dihydrochloride also block SARS-CoV-2 infection in colonic organoids [36]. Furthermore, using human colon-derived organoids, Stanifer, et al., demonstrated that pre-treatment of colon-derived organoids with both type I IFN (IFN- $\beta 1$ ) and type III IFN (IFN- $\lambda$ ) significantly blocked SARS-CoV-2 infection and this was related to a reduction in viral genome copy number [49].

\section{Brain organoids}

A mounting number of COVID-19 cases exhibit neurologic symptoms and neuropsychiatric disorders $[50,51]$, suggesting that the central nervous system (CNS) may be vulnerable to this virus. Human iPSCs-derived brain organoids have allowed several groups to independently examine the neurotropism and neurotoxic effects of SARS-CoV-2 in this pandemic. Ramani, et al., revealed that SARS-CoV-2 could infect human brain organoids within two days of virus exposure [52]. Interestingly, no productive replication of the virus could be observed in neural cells, supporting the hypothesis that SARS-CoV-2 can use the CNS as a long-term reservoir [53]. However, neurodegeneration-like effects consisting of extensive cell death and hyperphosphorylation, were observed in these neurons infected by SARS-CoV-2, associated with misallocation of the structural protein Tau [52]. Similarly, several studies also found that neurons including neural progenitor cells (NPCs) and mature cortical neurons in these organoids were observed to be infected by SARS-CoV-2 $[54,55]$. On the contrary, Bullen, et al., found an increased accumulation of viral particles in neuronal cells of brain organoids infected with SARS-CoV-2, indicating an active infection and replication of the virus in neurons [56]. These contradictory results may be due to differences in experimental conditions between studies by different teams, such as the time of SARS-CoV-2 infection and the adoption of iPSC-derived organoids at different differentiation and developmental stage.

A recent study systematically tested SARS-CoV-2 infection in various region-specific brain organoids of the hypothalamus, midbrain, hippocampus, and cortex [57]. Intriguingly, the choroid plexus epithelium expressed in hippocampal organoids were more vulnerable to the virus than neurons, suggesting that the choroid plexus epithelium is probably the gateway for the entry of the SARS-CoV-2 into the human brain. This possibility is supported by recent findings that show abundant expression of ACE2 and TMPRSS2 in choroid plexus epithelial cells $[58,59]$. The productive SARS-CoV-2 infection of choroid plexus organoids led to cell death, transcriptional upregulation of inflammatory genes, and functional deficits [57]. Pellegrini, et al., also found a stronger tropism of SARS-CoV-2 towards the choroid plexus than neurons within choroid plexus organoid cultures [59]. The infection by SARS-CoV-2 damages choroid plexus epithelial cells, leading to leakage of the blood-cerebrospinal fluid barrier which plays a vital role in preventing the entry of pathogens, immune cells, and cytokines into the cerebrospinal fluid and brain [59].

Human PSC-based brain organoids have become permissive to high-throughput drug screenings, consequently accelerating the discovery or repurposing of drugs for preventing and treating CNS related COVID-19 symptoms. Sofosbuvir, an FDA (US Food and Drug Administration)-approved nucleotide polymerase inhibitor [60], was used as a treatment for SARS-CoV-2 infection. Notably, this drug has been shown to decrease viral accumulation and reduce neuronal death in brain organoids, highlighting the potential abirritation for neurological symptoms [61]. Song, et al., found metabolic changes in SARS-CoV-2infected neurons in brain organoids, but no evidence of type I interferons (IFN-I) response was detected [54]. IgG antibodies against SARS-CoV-2 present in the cerebrospinal fluid from a patient hospitalized with COVID-19 were able to prevent virus infection of brain organoids [54]. Overall, these studies exhibit great potential of human PSC-based brain organoids for probing the infection of SARS-CoV-2 virus in the CNS.

\section{Liver organoids}

As liver damage has been observed in patients with COVID-19 [62], experimental platforms including human liver ductal organoids, hepatocyte and cholangiocyte organoids have been used as models of SARS-CoV-2 infection. Yang, et al., established adult liver hepatocyte and cholangiocyte organoids from bile duct epithelial cells and found a high expression of both ACE2 and TMPRSS2 in these organoid derivatives [63]. Liver hepatocyte and cholangiocyte organoids are permissive to both SARS-CoV-2 pseudo-entry virus and SARS-CoV-2 virus infection. SARS-CoV-2 infection caused 
significant expression of chemokines and upregulation of inflammatory pathways, as also seen in autopsy samples from patients with COVID-19 [63]. Zhao, et al., reported a liver ductal organoid model generated from liver bile duct-derived progenitor cells grown in a 3D culture system [64]. Cholangiocytes in human liver ductal organoids express ACE2 and TMPRSS2 that enable SARS-CoV-2 infection. Infected cells in liver ductal organoids overexpressed chemokines, formed syncytia and underwent extensive apoptosis with injury of the bile acid transporting functions, resulting in the accumulation or leakage of bile acid and a series of clinical symptoms in COVID-19 patients [64]. These observations suggest that the hepatic injury caused directly by SARS-CoV-2 infection should also be taken into account in treating COVID-19 patients. Together, hPSC-derived liver organoids provide a valuable platform for understanding the tropism and pathogenesis of SARS-CoV-2 and discovering prospective anti-viral therapeutics.

\section{Kidney organoids}

Given the presence of renal manifestations such as proteinuria, hematuria, and other classic symptoms in severe COVID-19 patients $[65,66]$ and the detection of this virus in the urine of infected individuals [67], human kidney organoids have also been tested as a model of SARS-CoV-2 infection. Kidney organoids were recently established from human ESCs, and can be directly infected by SARS-CoV-2 [68]. Consistent with widely expressed ACE2 in human kidney biopsies, ACE2 is expressed in podocytes and proximal tubular cells of human kidney organoids [68]. Another study generated long term cultures of organoids from human kidney proximal tubular epithelial cells and found that ACE2 was more highly expressed in 3D culture than in 2D cultured cells [69]. To confirm whether SARS-CoV-2 invades renal cells via ACE2, human recombinant soluble ACE2 (hrsACE2) was added to competitively bind to the virus rather than host cells $[68,70]$. As a result, hrsACE2 significantly decreased SARS-CoV-2 infection of kidney organoids in a dose-dependent manner without causing cell toxicity. Wysocki, et al., also proved the neutralizing effect of their modified long-acting ACE2 variants to resist SARS-CoV-2 in human kidney organoids [71]. Interestingly, hrsACE2 could markedly improve the effect of remdesivir in SARS-CoV-2 infection in kidney organoid cultures [70]. These observed efficacies of ACE2 in kidney organoids encourage further clinical investigation of this drug alone or in combination with other drugs.

\section{Cardiac and vascular organoids}

Cardiovascular complications are another common condition in patients with severe COVID-19 and increase the risk of mortality [72-74]. Human PSC-based cardiac organoids [75, 76] and vascular organoids [68] have been established as potential in vitro models to study SARS-CoV-2 infection in the cardiovascular system. The high expression of ACE2 has been observed in cardiomyocytes, endothelial cells, vascular smooth muscle cells, and pericytes lining blood vessels $[77,78]$.

Mills et al., developed a high-throughput hPSCcardiac organoid platform, using it to screen 105 small molecules with regenerative potential. These organoids could also be a feasible platform to study virus infection and screen antiviral drugs [79]. Recently, by using human cardiac organoids, Mills, et al., showed that bromodomain and extraterminal family inhibitors (BETi) reduced ACE2 expression, decreased transcription of genes in the viral response, and blocked SARS-CoV-2 infection of cardiomyocytes and inflammation-induced cardiac dysfunction [76]. By using iPSC-derived blood vessel organoids, Monteil, et al., validated that SARS-CoV-2 was able to infect human blood vessels [68]. Importantly, the virus replication was detected in these organoids after infection. The addition of clinical-grade hrsACE2 dramatically reduced SARS-CoV-2 infections of human blood vessel organoids [68]. Consistently, organoids infected with mixtures of SARS-CoV-2 virus particles and variable concentrations of hrsACE2 have markedly decreased levels of intracellular viral RNA [68]. These findings may explain how the virus spreads through the body and leads to organ damage in severely ill individuals.

\section{Eye organoids}

Recent clinical evidence has shown that a minority of COVID-19 patients present with ocular symptoms [80, 81]. Importantly, SARS-CoV-2 entry factors ACE2 and TMPRSS2 have been found to be expressed in the limbal, corneal, and conjunctival epithelium of the eye and their organoid derivatives [82-85]. Also, SARS-CoV-2 viruses have been detected in the conjunctiva of infected rhesus monkeys [86]. These findings indicate that ocular surfaces may serve as an additional entry vector for SARS-CoV-2. Therefore, eyes are at risk for infection by SARS-CoV-2 and are a route warranting protection. Human iPSC-derived whole-eye organoid models, which are comprised of cells from the retina, cornea, ciliary margin, retinal pigment epithelium, lens and iris as well as cell monolayers grown from limbal, corneal and conjunctival epithelium, have been established to study SARS-CoV-2 ocular infection 
[84]. In fact, the corneal limbus seems to be the most susceptible to infection, consistent with its high expression of ACE2 and TMPRSS2, essential proteins that mediate SARS-CoV-2 viral entry. This means that the cornea may be the entrance and proliferation site of virus infection. Although IFN-I and IFN-III were not detected, human eye organoids mounted a significant inflammatory response indicative of NF-KB signaling [84]. Similar findings were obtained from ocular biopsies from human beings infected with SARS-CoV-2, supporting the utility of eye organoids to study SARS-CoV-2 infection and identify prophylactics that may protect the eyes from infection [84]. Future studies are required to better clarify how infection in the eye may lead to transmission to other regions of the body.

\section{Limitations and perspectives}

Exploring the life cycle of SARS-CoV-2 and unearthing the efficacy of drugs can be made more objective by using organoid models. Organoids models can simulate the pathology of COVID-19 in corresponding tissues, and provide a valuable platform for unraveling virus infectivity, tropisms, replication kinetics and potential treatments $[87,88]$. Although a range of new studies demonstrated many more advantages of human organoids, these models still have some limitations. The microenvironment of organoids differs from the native organ to some extent due to the absence of additional cell types such as fibroblasts, vascular cells, neural cells and immune cells. In general, iPSC-derived organoids can contain mesenchymal lineages such as fibroblasts, while ASC-derived organoids consist exclusively of epithelial cells [89]. Moreover, organoid models cannot fully represent the systemic symptoms associated with whole body responses to this disease. This means virology research using organoids will still need to be validated in animal models and clinical studies. Anyhow, it is worth noting that organoids exhibit greater complexity and resemble the true organ more closely than any other 2D cultured cells.

Immune cells play a vital role in the fight against SARS-CoV-2 infection [90]. Organoids derived from non-small-cell lung cancer and colorectal cancer have been co-cultured with $\mathrm{T}$ cells from individual patients $[91,92]$. The co-culture system showed successful antigen presentation of tumor organoid cells to T cells, which subsequently became activated [92]. Immune co-cultured organoids can also be applied to virus infection research to understanding COVID-19 immune responses. Furthermore, several studies have reported promising organoid-based findings, including the bioengineering of a scaffold-guided functional intestine using a bioreactor $[93,94]$ and organoids-on-a-chip [95]. Such physiologically relevant culture systems, as well as functional simulation of immune responses in bioengineered organoids, will open up new perspectives for disease modelling to help fight the current pandemic.

\section{Abbreviations}

2D: two-dimensional; 3D: three-dimensional; ACE2: angiotensin-converting enzyme 2; ALI: air-liquid interface; ASC: adult stem cell; AT1: alveolar type-I; AT2: alveolar type-II; BETi: bromodomain and extraterminal family inhibitors; CNS: central nervous system; COVID-19: coronavirus disease 2019; ESC: embryonic stem cell; FDA: Food and Drug Administration; hrsACE2: human recombinant soluble angiotensin-converting enzyme 2; HBV: hepatitis B virus; hPSC: human pluripotent stem cell; HPV: human papillomavirus; HSV: herpes simplex virus; iPSC: induced pluripotent stem cell; IFN-I: type I interferon; IFN-III: type III interferon; IFN- $\lambda 1$ : interferon lambda 1; IL: Interleukin; MERS-CoV: Middle East respiratory syndrome coronavirus; MPA: mycophenolic acid; NF-KB: nuclear factor kappa beta; NPC: neural progenitor cell; PSC: pluripotent stem cell; QNHC: quinacrine dihydrochloride; SARS-CoV-2: severe acute respiratory syndrome coronavirus 2; RSV: respiratory syncytial virus; TMPRSS2: transmembrane serine protease 2; TNF: tumor necrosis factor; ZIKV: Zika virus.

\section{Acknowledgements}

This work was supported by the National Key R\&D Program of China (No. 2019YFA0906000), the China Postdoctoral Science Foundation (No. 2021M692159), the Shenzhen Key Medical Discipline Construction Fund (No. SZXK017), the Shenzhen San-Ming Project (No. SZSM201612010), and the Shenzhen High-level Hospital Construction Fund. We also thank Lisa Liu (Temple University) for comments and advice on this paper.

\section{Competing Interests}

The authors have declared that no competing interest exists.

\section{References}

1. Shi J, Wen Z, Zhong G, Yang H, Wang C, Huang B, et al. Susceptibility of ferrets, cats, dogs, and other domesticated animals to SARS-coronavirus 2. Science. 2020; 368:1016-20.

2. Park SJ, Yu KM, Kim YI, Kim SM, Kim EH, Kim SG, et al. Antiviral Efficacies of FDA-Approved Drugs against SARS-CoV-2 Infection in Ferrets. mBio. 2020; 11:e01114-20.

3. Shan C, Yao YF, Yang XL, Zhou YW, Gao G, Peng Y, et al. Infection with novel coronavirus (SARS-CoV-2) causes pneumonia in Rhesus macaques. Cell Res. 2020; 30:670-7.

4. Rockx B, Kuiken T, Herfst S, Bestebroer T, Lamers MM, Oude Munnink BB, et al. Comparative pathogenesis of COVID-19, MERS, and SARS in a nonhuman primate model. Science. 2020; 368:1012-5. 
5. Sia SF, Yan LM, Chin AWH, Fung $\mathrm{K}$, Choy KT, Wong AYL, et al. Pathogenesis and transmission of SARS-CoV-2 in golden hamsters. Nature. 2020; 583:834-8

6. Hoffmann M, Kleine-Weber H, Schroeder S, Krüger N, Herrler T, Erichsen S, et al. SARS-CoV-2 cell entry depends on ACE2 and TMPRSS2 and is blocked by a clinically proven protease inhibitor. Cell. 2020; 181:271-80.e8.

7. Matsuyama S, Nao N, Shirato K, Kawase M, Saito S, Takayama I, et al. Enhanced isolation of SARS-CoV-2 by TMPRSS2-expressing cells. Proc Natl Acad Sci U S A. 2020; 117:7001-3.

8. Bao L, Deng W, Huang B, Gao H, Liu J, Ren L, et al. The pathogenicity of SARS-CoV-2 in hACE2 transgenic mice. Nature. 2020; 583(7818):830-3.

9. Chu H, Chan JF, Yuen TT, Shuai H, Yuan S, Wang Y, et al. Comparative tropism, replication kinetics, and cell damage profiling of SARS-CoV-2 and SARS-CoV with implications for clinical manifestations, transmissibility, and laboratory studies of COVID-19: an observational study. Lancet Microbe. 2020; 1:e14-e23.

10. Jeon S, Ko M, Lee J, Choi I, Byun SY, Park S, et al. Identification of Antiviral Drug Candidates against SARS-CoV-2 from FDA-Approved Drugs. Antimicrob Agents Chemother. 2020; 64:e00819-20.

11. Clevers H. Modeling Development and Disease with Organoids. Cell. 2016; 165:1586-97.

12. Lancaster MA, Knoblich JA. Organogenesis in a dish: modeling development and disease using organoid technologies. Science. 2014; 345:1247125.

13. Dutta D, Heo I, Clevers H. Disease Modeling in Stem Cell-Derived 3D Organoid Systems. Trends Mol Med. 2017; 23:393-410.

14. Rossi G, Manfrin A, Lutolf MP. Progress and potential in organoid research. Nat Rev Genet. 2018; 19:671-87.

15. Chen YW, Huang SX, de Carvalho ALRT, Ho SH, Islam MN, Volpi S, et al. A three-dimensional model of human lung development and disease from pluripotent stem cells. Nat Cell Biol. 2017; 19:542-9.

16. Driehuis E, Kolders S, Spelier S, Lõhmussaar K, Willems SM, Devriese LA, et al. Oral Mucosal Organoids as a Potential Platform for Personalized Cancer Therapy. Cancer Discov. 2019; 9:852-71.

17. Estes MK, Ettayebi K, Tenge VR, Murakami K, Karandikar U, Lin SC, et al. Human Norovirus Cultivation in Nontransformed Stem Cell-Derived Human Intestinal Enteroid Cultures: Success and Challenges. Viruses. 2019; 11:638.

18. Ettayebi K, Crawford SE, Murakami K, Broughman JR, Karandikar U, Tenge VR, et al. Replication of human noroviruses in stem cell-derived human enteroids. Science. 2016; 353:1387-93.

19. Haga K, Ettayebi K, Tenge VR, Karandikar UC, Lewis MA, Lin SC, et al. Genetic Manipulation of Human Intestinal Enteroids Demonstrates the Necessity of a Functional Fucosyltransferase 2 Gene for Secretor-Dependent Human Norovirus Infection. mBio. 2020; 11:e0251-20.

20. Qian X, Nguyen HN, Jacob F, Song H, Ming GL. Using brain organoids to understand Zika virus-induced microcephaly. Development. 2017; 144:952-957.

21. Sachs N, Papaspyropoulos A, Zomer-van Ommen DD, Heo I, Böttinger L, Klay D, et al. Long-term expanding human airway organoids for disease modeling. EMBO J. 2019; 38:e100300.

22. Watanabe M, Buth JE, Vishlaghi N, de la Torre-Ubieta L, Taxidis J, Khakh BS. Self-organized cerebral organoids with human-specific features predict effective drugs to combat Zika virus infection. Cell Rep. 2017; 21:517-32.

23. Zhou J, Li C, Sachs N, Chiu MC, Wong BH, Chu H, et al. Differentiated human airway organoids to assess infectivity of emerging influenza virus. Proc Natl Acad Sci U S A. 2018; 115:6822-7.

24. Hui KPY, Ching RHH, Chan SKH, Nicholls JM, Sachs N, Clevers $\mathrm{H}$, et al. Tropism, replication competence, and innate immune responses of influenza virus: an analysis of human airway organoids and ex-vivo bronchus cultures. Lancet Respir Med. 2018; 6:846-54.

25. Zhou J, Li C, Zhao G, Chu H, Wang D, Yan HH, et al. Human intestinal tract serves as an alternative infection route for Middle East respiratory syndrome coronavirus. Sci Adv. 2017; 3:eaao4966.

26. Gabriel E, Ramani A, Karow U, Gottardo M, Natarajan K, Gooi LM, et al. Recent Zika Virus Isolates Induce Premature Differentiation of Neural Progenitors in Human Brain Organoids. Cell Stem Cell. 2017; 20:397-406.e5.

27. Qian X, Nguyen HN, Song MM, Hadiono C, Ogden SC, Hammack C, et a Brain-region-specific organoids using mini-bioreactors for modeling ZIKV exposure. Cell. 2016; 165:1238-54

28. Sison SL, O'Brien BS, Johnson AJ, Seminary ER, Terhune SS, Ebert AD. Human Cytomegalovirus Disruption of Calcium Signaling in Neural Progenitor Cells and Organoids. J Virol. 2019; 93:e00954-19.

29. Nie YZ, Zheng YW, Miyakawa K, Murata S, Zhang RR, Sekine K, et al. Recapitulation of hepatitis B virus-host interactions in liver organoids from human induced pluripotent stem cells. EBioMedicine. 2018; 35:114-23.

30. Oudit GY, Imai Y, Kuba K, Scholey JW, Penninger JM. The role of ACE2 in pulmonary diseases-relevance for the nephrologist. Nephrol Dial Transplant. 2009; 24:1362-5.

31. Lamers MM, Beumer J, van der Vaart J, Knoops K, Puschhof J, Breugem TI, et al. SARS-CoV-2 productively infects human gut enterocytes. Science. 2020; $369 \cdot 50-4$

32. Lamers MM, van der Vaart J, Knoops K, Riesebosch S, Breugem TI, Mykytyn $\mathrm{AZ}$, et al. An organoid-derived bronchioalveolar model for SARS-CoV-2 infection of human alveolar type II-like cells. EMBO J. 2021; 40:e105912.

33. Ebisudani T, Sugimoto S, Haga K, Mitsuishi A, Takai-Todaka R, Fujii M, et al. Direct derivation of human alveolospheres for SARS-CoV-2 infection modeling and drug screening. Cell Rep. 2021;35:109218.
34. Salahudeen AA, Choi SS, Rustagi A, Zhu J, van Unen V, de la O SM, et al. Progenitor identification and SARS-CoV-2 infection in human distal lung organoids. Nature. 2020; 588:670-5.

35. Tindle C, Fuller M, Fonseca A, Taheri S, Ibeawuchi SR, Beutler N, et al. Adult stem cell-derived complete lung organoid models emulate lung disease in COVID-19. Elife. 2021; 10:e66417.

36. Han Y, Duan X, Yang L, Nilsson-Payant BE, Wang P, Duan F, et al. Identification of SARS-CoV-2 inhibitors using lung and colonic organoids. Nature. 2021; 589:270-5.

37. Pei R, Feng J, Zhang Y, Sun H, Li L, Yang X, et al. Host metabolism dysregulation and cell tropism identification in human airway and alveolar organoids upon SARS-CoV-2 infection. Protein Cell. 2020; 1-17.

38. Leibel SL, McVicar RN, Winquist AM, Niles WD, Snyder EY. Generation of Complete Multi-Cell Type Lung Organoids From Human Embryonic and Patient-Specific Induced Pluripotent Stem Cells for Infectious Disease Modeling and Therapeutics Validation. Curr Protoc Stem Cell Biol. 2020; 54:e118.

39. Samuel RM, Majd H, Richter MN, Ghazizadeh Z, Zekavat SM, Navickas A, et al. Androgen Signaling Regulates SARS-CoV-2 Receptor Levels and Is Associated with Severe COVID-19 Symptoms in Men. Cell Stem Cell. 2020; 27:876-89.e12.

40. Suzuki T, Ito Y, Sakai Y, Saito A, Okuzaki D, Motooka D, et al. Generation of human bronchial organoids for SARS-CoV-2 research. Preprint. bioRxiv. 2020; 2020.05.25.115600. doi: 10.1101/2020.05.25.115600.

41. Shi R, Shan C, Duan X, Chen Z, Liu P, Song J, et al. A human neutralizing antibody targets the receptor-binding site of SARS-CoV-2. Nature. 2020; 584:120-4.

42. Gupta A, Madhavan MV, Sehgal K, Nair N, Mahajan S, Sehrawat TS, et al. Extrapulmonary manifestations of COVID-19. Nat Med. 2020; 26:1017-32.

43. Zhou J, Li C, Liu X, Chiu MC, Zhao X, Wang D, et al. Infection of bat and human intestinal organoids by SARS-CoV-2. Nat Med. 2020; 26:1077-83.

44. Zang R, Gomez Castro MF, McCune BT, Zeng Q, Rothlauf PW, Sonnek NM, et al. TMPRSS2 and TMPRSS4 promote SARS-CoV-2 infection of human small intestinal enterocytes. Sci Immunol. 2020; 5:eabc3582.

45. Krüger J, Groß R, Conzelmann C, Müller JA, Koepke L, Sparrer KMJ, et al. Drug inhibition of SARS-CoV-2 replication in human pluripotent stem cell-derived intestinal organoids. Cell Mol Gastroenterol Hepatol. 2021; 11:935-48.

46. Beigel JH, Tomashek KM, Dodd LE. Remdesivir for the Treatment of Covid-19-Preliminary Report. Reply. N Engl J Med. 2020; 383:994.

47. Freedberg DE, Conigliaro J, Wang TC, Tracey KJ, Callahan MV, Abrams JA, et al. Famotidine use is associated with improved clinical outcomes in hospitalized COVID-19 patients: A propensity score matched retrospective cohort study. Gastroenterology. 2020; 159:1129-31.e3.

48. Xia S, Liu M, Wang C, Xu W, Lan Q, Feng S, et al. Inhibition of SARS-CoV-2 (previously 2019-nCoV) infection by a highly potent pan-coronavirus fusion inhibitor targeting its spike protein that harbors a high capacity to mediate membrane fusion. Cell Res. 2020; 30:343-55.

49. Stanifer ML, Kee C, Cortese M, Zumaran CM, Triana S, Mukenhirn M, et al. Critical Role of Type III Interferon in Controlling SARS-CoV-2 Infection in Human Intestinal Epithelial Cells. Cell Rep. 2020; 32:107863.

50. Ellul MA, Benjamin L, Singh B, Lant S, Michael BD, Easton A, et al. Neurological associations of COVID-19. Lancet Neurol. 2020; 19:767-83.

51. Iadecola C, Anrather J, Kamel H. Effects of COVID-19 on the Nervous System. Cell. 2020; 183:16-27.e1.

52. Ramani A, Müller L, Ostermann PN, Gabriel E, Abida-Islam P, Müller-Schiffmann A, et al. SARS-CoV-2 targets neurons of 3D human brain organoids. EMBO J. 2020; 39:e106230.

53. Gomez-Pinedo U, Matias-Guiu J, Sanclemente-Alaman I, Moreno-Jimenez L, Montero-Escribano P, Matias-Guiu JA. Is the brain a reservoir organ for SARS-CoV2?. J Med Virol. 2020; 92:2354-5.

54. Song $\mathrm{E}$, Zhang $\mathrm{C}$, Israelow $\mathrm{B}$, Lu-Culligan $\mathrm{A}$, Prado AV, Skriabine $\mathrm{S}$, et al Neuroinvasion of SARS-CoV-2 in human and mouse brain. J Exp Med. 2021; 218:e20202135

55. Zhang BZ, Chu H, Han S, Shuai H, Deng J, Hu YF, et al. SARS-CoV-2 infects human neural progenitor cells and brain organoids. Cell Res. 2020; 30:928-31.

56. Bullen CK, Hogberg HT, Bahadirli-Talbott A, Bishai WR, Hartung T, Keuthan C, et al. Infectability of human BrainSphere neurons suggests neurotropism of SARS-CoV-2. ALTEX. 2020; 37:665-71.

57. Jacob F, Pather SR, Huang WK, Zhang F, Wong SZH, Zhou H, et al. Human pluripotent stem cell-derived neural cells and brain organoids reveal SARS-CoV-2 neurotropism predominates in choroid plexus epithelium. Cell Stem Cell. 2020; 27:937-50.e9.

58. Deffner F, Scharr M, Klingenstein S, Klingenstein M, Milazzo A, Scherer S, et al. Histological Evidence for the Enteric Nervous System and the Choroid Plexus as Alternative Routes of Neuroinvasion by SARS-CoV2 Front Neuroanat. 2020; 14:596439.

59. Pellegrini L, Albecka A, Mallery DL, Kellner MJ, Paul D, Carter AP, et al. SARS-CoV-2 infects the brain choroid plexus and disrupts the blood-CSF-barrier in human brain organoids. Cell Stem Cell. 2020; 27:951-61.

60. Bhatia HK, Singh H, Grewal N, Natt NK. Sofosbuvir: A novel treatment option for chronic hepatitis $C$ infection. J Pharmacol Pharmacother. 2014; 5·278-84.

61. Mesci P, Macia A, Saleh A, Martin-Sancho L, Yin X, Snethlage C, et al. Sofosbuvir protects human brain organoids against SARS-CoV-2. Preprint.vbioRxiv. 2020; 2020.05.30.125856. doi: 10.1101/2020.05.30.125856. 
62. Zhang C, Shi L, Wang FS. Liver injury in COVID-19: management and challenges. Lancet Gastroenterol Hepatol. 2020; 5:428-30.

63. Yang L, Han Y, Nilsson-Payant BE, Gupta V, Wang P, Duan X, et al. A human pluripotent stem cell-based platform to study SARS-CoV-2 tropism and model virus infection in human cells and organoids. Cell Stem Cell. 2020; 27:125-36.e7.

64. Zhao B, Ni C, Gao R, Wang Y, Yang L, Wei J, et al. Recapitulation of SARS-CoV-2 infection and cholangiocyte damage with human liver ductal organoids. Protein Cell. 2020; 11:771-5.

65. Kunutsor SK, Laukkanen JA. Renal complications in COVID-19: Aystematic review and meta-analysis. Ann Med. 2020; 52:345-53.

66. Qian JY, Wang B, Liu BC. Acute Kidney Injury in the 2019 Novel Coronavirus Disease. Kidney Dis (Basel). 2020; 323:1-6.

67. Ling $\mathrm{Y}, \mathrm{Xu} \mathrm{SB}$, Lin $\mathrm{YX}$, Tian $\mathrm{D}$, Zhu ZQ, Dai FH, et al. Persistence and clearance of viral RNA in 2019 novel coronavirus disease rehabilitation patients. Chin Med J (Engl). 2020; 133:1039-43.

68. Monteil V, Kwon H, Prado P, Hagelkrüys A, Wimmer RA, Stahl M, et al. Inhibition of SARS-CoV-2 infections in engineered human tissues using clinical-grade soluble human ACE2. Cell. 2020; 181:905-13.e7.

69. Xia S, Wu M, Chen S, Zhang T, Ye L, Liu J, et al. Long Term Culture of Human Kidney Proximal Tubule Epithelial Cells Maintains Lineage Functions and Serves as an Ex vivo Model for Coronavirus Associated Kidney Injury. Virol Sin. 2020; 35:311-20.

70. Monteil V, Dyczynski M, Lauschke VM, Kwon H, Wirnsberger G, Youhanna S, et al. Human soluble ACE2 improves the effect of remdesivir in SARS-CoV-2 infection. EMBO Mol Med. 2021; 13:e13426.

71. Wysocki J, Ye M, Hassler L, Gupta AK, Wang Y, Nicoleascu V, et al. A novel soluble ACE2 variant with prolonged duration of action neutralizes SARS-CoV-2 infection in human kidney organoids. J Am Soc Nephrol. 2021; 32:795-803.

72. Guo T, Fan $\mathrm{Y}$, Chen $\mathrm{M}, \mathrm{Wu} \mathrm{X}$, Zhang $\mathrm{L}, \mathrm{He} \mathrm{T}$, et al. Cardiovascular implications of fatal outcomes of patients with coronavirus disease 2019 (COVID-19). JAMA Cardiol. 2020; 5: 811-8.

73. Varga Z, Flammer AJ, Steiger P, Haberecker M, Andermatt R, Zinkernagel AS, et al. Endothelial cell infection and endotheliitis in COVID-19. Lancet. 2020; 395:1417-8.

74. Zheng YY, Ma YT, Zhang JY, Xie X. COVID-19 and the cardiovascular system. Nat Rev Cardiol. 2020; 17:259-60.

75. Marchiano S, Hsiang TY, Khanna A, Higashi T, Whitmore LS, Bargehr J, et al. SARS-CoV-2 infects human pluripotent stem cell-derived cardiomyocytes, impairing electrical and mechanical function. Stem Cell Reports. 2021; 16:478-92.

76. Mills RJ, Humphrey SJ, Fortuna PRJ, Lor M, Foster SR, Quaife-Ryan GA, et al. BET inhibition blocks inflammation-induced cardiac dysfunction and SARS-CoV-2 infection. Cell. 2021; 184: 2167-82.e22.

77. Nicin L, Abplanalp WT, Mellentin H, Kattih B, Tombor L, John D, et al. Cell type-specific expression of the putative SARS-CoV-2 receptor ACE2 in human hearts. Eur Heart J. 2020; 41:1804-6.

78. Tucker NR, Chaffin M, Bedi KC Jr, Papangeli I, Akkad AD, Arduini A, et al. Myocyte-Specific Upregulation of ACE2 in Cardiovascular Disease: Implications for SARS-CoV-2-Mediated Myocarditis. Circulation. 2020; 142:708-10.

79. Mills RJ, Parker BL, Quaife-Ryan GA, Voges HK, Needham EJ, Bornot A, et al. Drug screening in human PSC-cardiac organoids identifies pro-proliferative compounds acting via the mevalonate pathway. Cell Stem Cell. 2019; 24:895-907.e6

80. Colavita F, Lapa D, Carletti F, Lalle E, Bordi L, Marsella P, et al. SARS-CoV-2 Isolation From Ocular Secretions of a Patient With COVID-19 in Italy With Prolonged Viral RNA Detection. Ann Intern Med. 2020; 173:242-3.

81. Zhou Y, Duan C, Zeng Y, Tong Y, Nie Y, Yang Y, et al. Ocular Findings and Proportion with Conjunctival SARS-COV-2 in COVID-19 Patients. Ophthalmology. 2020; 127:982-3.

82. Ahmad Mulyadi Lai HI, Chou SJ, Chien Y, Tsai PH, Chien CS, Hsu CC, et al. Expression of endogenous angiotensin-converting enzyme 2 in human induced pluripotent stem cell-derived retinal organoids. Int J Mol Sci. 2021; 22:1320.

83. Collin J, Queen R, Zerti D, Dorgau B, Georgiou M, Djidrovski I, et al. Co-expression of SARS-CoV-2 entry genes in the superficial adult human conjunctival, limbal and corneal epithelium suggests an additional route of entry via the ocular surface. Ocul Surf. 2021; 19:190-200.

84. Makovoz B, Moeller R, Zebitz Eriksen A, tenOever BR, Blenkinsop TA. SARS-CoV-2 infection of ocular cells from human adult donor eyes and hESC-derived eye organoids. Preprint. SSRN. 2020; 3650574.

85. Zhou L, Xu Z, Castiglione GM, Soiberman US, Eberhart CG, Duh EJ. ACE2 and TMPRSS2 are expressed on the human ocular surface, suggesting susceptibility to SARS-CoV-2 infection. Ocul Surf. 2020; 18:537-44.

86. Aiello F, Gallo Afflitto G, Mancino R, Li JO, Cesareo M, Giannini C, et al. Coronavirus disease 2019 (SARS-CoV-2) and colonization of ocular tissues and secretions: a systematic review. Eye (Lond). 2020; 34:1206-11

87. Busquet F, Hartung T, Pallocca G, Rovida C, Leist M. Harnessing the power of novel animal-free test methods for the development of COVID-19 drugs and vaccines. Arch Toxicol. 2020; 94:2263-72.

88. Takayama K. In vitro and animal models for SARS-CoV-2 research. Trends Pharmacol Sci. 2020; 41:513-7.
89. Geurts $\mathrm{MH}$, van der Vaart J, Beumer J, Clevers H. The Organoid Platform: Promises and Challenges as Tools in the Fight against COVID-19. Stem Cell Reports. 2021; 16:412-8.

90. Vabret N, Britton GJ, Gruber C, Hegde S, Kim J, Kuksin M, et al. Immunology of COVID-19: Current State of the Science. Immunity. 2020; 52:910-41.

91. Cattaneo CM, Dijkstra KK, Fanchi LF, Kelderman S, Kaing S, van Rooij N, et al. Tumor organoid-T-cell coculture systems. Nat Protoc. 2020; 15:15-39.

92. Dijkstra KK, Cattaneo CM, Weeber F, Chalabi M, van de Haar J, Fanchi LF, et al. Generation of Tumor-Reactive T Cells by Co-culture of Peripheral Blood Lymphocytes and Tumor Organoids. Cell. 2018; 174:1586-98.e12.

93. Meran L, Massie I, Campinoti S, Weston AE, Gaifulina R, Tullie L, et al. Engineering transplantable jejunal mucosal grafts using patient- derived organoids from children with intestinal failure. Nat Med. 2020; 26:1593-601.

94. Nikolaev M, Mitrofanova O, Broguiere N, Geraldo S, Dutta D, Tabata Y, et al. Homeostatic mini-intestines through scaffold-guided organoid morphogenesis. Nature. 2020; 585:574-8.

95. Park SE, Georgescu A, Huh D. Organoids-on-a-chip. Science. 2019; 364:960-5. 